\title{
Analysis of Employee's Job Involvement Difference Based on Individual Character
}

\author{
An Example of Hospitality Industry
}

\author{
Xiaobing Feng \\ College of Tourism \\ Leshan Normal University \\ Leshan, China 614000
}

\begin{abstract}
As a positive work condition, it causes an increasingly concern among organizational behavior and human resource management scholars. The hotel product has its special identity that producing and consuming simultaneously. The specificity needs employees to maintain a high degree of job involvement when working. Taking the high-star hotel as the research object, the paper used factor analysis to probe the structure of hotel employee's job involvement, and analyzed the differences of job involvement among hotel employee's individual character.
\end{abstract}

\section{Keywords—job involvement; tructure; individual character}

\section{INTRODUCTION}

With the rise of positive psychology and active organizational behavior, job involvement as an individual's active working condition has entered the attention of the researcher [1], and is increasingly receiving attention in the fields of psychology, organizational behavior, and human resource management. "Job Involvement" was first proposed by Kahn in 1990. It is considered that job involvement is the control of self-organization members to combine self and work roles [2]. Schaufeli (2002) believes that job involvement is a positive, full emotional and cognitive state related to work [3]. Paullay (1994) believes that job involvement is the degree to which the individual is cognitively focused, cared, and hard-working on current work [4]. Chen Weizheng (2006) believes that job involvement refers to employees' personal recognition of their work psychologically or cognitively to the importance of work for themselves [5]. Xu Yan (2007) defined the job involvement as the individual's psychological recognition of the current job and his emphasis on job performance during the work process, while being able to actively participate in the work [6]. Liu Wenqing (2007) believes that working investment is a kind of personal initiative and a degree of devotion to the work [7].The hotel is a company that provides services to customers. It has the characteristics of simultaneous production and consumption. The process of customer consumption is the process of hotel production. At the same time, the hotel's service quality is presented in a one-off manner. Therefore, Employees are required to maintain a high level of job involvement during the service process. As a labor-intensive and emotionally-intensive industry, the hotel industry must not only perform manual work but also behave emotionally when it comes in contact with customers. High-intensity work can easily cause job burnout and affect employees. Studies have shown that positive work emotions are conducive to improving employee job satisfaction and job performance, and even have an important role in improving organizational performance [8]. Therefore, the research on the job involvement of hotel staff is very necessary.

\section{MeASUREMENT OF JoB INVOLVEMENT}

With regard to the structure of job involvement, scholars mostly agree with the three-dimensional model of job involvement, but the specific indicators for investment in evaluation work are still in a state of dispute. When Kahn (1990) put forward the concept of job involvement, the job involvement was divided into three dimensions: physiological input, cognitive input and emotional input[2]. Maslach (1997), starting from the opposite of job burnout, believes that job involvement includes three dimensions of energy, involvement, and efficacy[9]. Schaufeli (2002) also starts from the relationship between job involvement and job burnout, and considers that job involvement includes three dimensions of vitality, dedication, and concentration[3]. Schaufeli's three-dimensional model is widely used in research. Chinese scholars put forward different views on this basis. Xu Yan (2005) proposed the four-dimensional structure of job involvement: interest orientation, job identification, and work enthusiasm. With active participation [10], Sheng Jiansen (2006) divided the job involvement into three dimensions of work importance, work fun, and work focus [11]. May compiled a pre-testing scale for measuring job involvement, extracted three factors of physiological input, cognitive input, and emotional input through exploratory factor analysis, and finally selected 13 of them to form a total job involvement scale.[12]. Maslach directly uses the job burnout questionnaire (MBI) to measure job involvement. The lower the score of job burnout, the higher the work load [9]. Schaufeli has developed the Utrecht Work Engagement Scale (UWES), which contains three subscales of vitality, dedication and focus, and is divided into two versions: full-scale (17 projects) and simplified version (9 projects).[3]. Chinese scholar Zhang 
Haowen revised the scale and found that the revised Chinese version of the UWES scale has maintained good reliability and validity in different cultures and different groups. It can be applied to domestic related research [13]. The study's evaluation of work involvement was conducted using Schaufeli's vitality, dedication, and focus on the threedimensional structure and using the revised Chinese version of the UWES scale (full version) for specific measurements.

\section{ANALYSIS OF THE STRUCTURE OF JOB INVOLVEMENT OF HOTEL STAFF}

\section{A. Reliability Analysis}

The reliability analysis was performed on the revised total volume table of the staff of the hotel staff and the subscales of each dimension. The reliability coefficient of the total amount of job involvement was 0.910, and the reliability of the vitality, concentration, and dedication scales was 0.810 , respectively. $0.747,0.867$, the reliability test value of the scale is all above 0.7, indicating that the reliability of the scale is good.

\section{B. Validity Analysis}

The KMO value of the hotel staff's job involvement scale is 0.904, which is suitable for factor analysis; the Bartlett sphericity test has significant water value of $0.000<0.001$, indicating that the correlation matrix is not an identity matrix and the indicators are relevant. Do factor analysis. For factor analysis, the principal component analysis method is used to extract factors with eigenvalues greater than 1 , and then the analysis results are rotated using the maximum variance method. The first factor analysis extracted a total of 3 common factors, and the cumulative contribution rate of the 3 common factors reached $58.214 \%$. The deletion factor load had a score of less than 0.5 on the three principal components or two items with a score greater than 0.5. "I can work continuously for a few weeks without rest," "I will reach the realm of selflessness at work". I will again perform factor analysis on 15 items and extract a total of three common factors. The accumulation of the three common factors The contribution rate reaches $60.589 \%$, which can basically explain the information of 15 original items. At the same time, the factor load of each item in the study is more than 0.5 , and the better load is on the respective factor.

According to the results in the following table, the structure of hotel employees' work involvement mainly includes three dimensions. Combining the meanings expressed by various factors, Schaufeli's vitality, dedication and three-dimensional structure of dedication are used to name factor 1 as "dedicated", including B9, B10, B11, B12, A13, B14, B15; Factor 2 is named "Vibration", including B1, B2, B3, B4, and B5; Factor 3 is named "Concentration", including B6, B7, and B8.

TABLE I. JOB INVOLVEMENT FACTOR ANALYSIS RotATIONAL COMPONENT MATRIX

\begin{tabular}{|c|c|c|c|}
\hline & Ingre & & \\
\hline & 1 & 2 & 3 \\
\hline I feel energetic at work. & .723 & & \\
\hline I think the purpose of the job is clear and meaningful. & .730 & & \\
\hline Although I sometimes work hard, I feel happy physically and mentally. & .582 & & \\
\hline At work, I feel very capable. & .714 & & \\
\hline I am passionate about my work. & .586 & & \\
\hline When working, I will forget the people and things around. & & .861 & \\
\hline Immersed in my work, often forget the time. & & .555 & \\
\hline After getting up in the morning, I'd be happy to work. & & .560 & \\
\hline What I do can inspire me. & & & 610 \\
\hline I felt happy when I was fully engaged in work. & & & .522 \\
\hline I am proud of the work I do. & & & .728 \\
\hline Even if I feel tired while working, I can recover quickly . & & & .705 \\
\hline For me, the work is challenging . & & & .750 \\
\hline Even if the work is not going well, I can keep up with it. & & & .660 \\
\hline I am full of feelings about my work. & & & 668 \\
\hline
\end{tabular}

IV. ANALYSIS OF THE INFLUENCE OF INDIVIDUAL CHARACTERISTICS ON HOTEL EMPLOYEES' JOB INVOLVEMENT

\section{A. Analysis of the Influence of Gender on the Job Involvement of Hotel Staff}

The mean value of the employee's work engagement energy dimension is higher than that of the focus and dedication. The average value of the energy and dedication dimension of the male employee in the work is higher than that of the female. The female employee is more focused than the male employee, but the three dimensions of the job involvement correspond. The value of sig. is greater than 0.05 , indicating that there is a significant gender difference in the degree of work commitment of hotel staff.

\section{B. Analysis of the Influence of Age on the Job Involvement of Hotel Staff}

In terms of vitality, the 31-35-year-old employees have the highest average value and the 20-24-year-old employees have the lowest average value; in terms of concentration, the 
average value of the employees under the age of 19 is the highest, and the average value of the employees over the age of 41 is the lowest; in terms of dedication, 31-35 years old The average value of employees is the highest, and the average of employees aged 41 and over is the lowest. Employees under the age of 19 have relatively short working hours in the hotel industry and are in the early stages of their career development. They maintain a high value in all aspects of their job involvement; 31-35 year-old employees are in the middle of their career development, and most of them have already with certain achievements, they also maintain a high degree of work commitment. Employees over the age of 41 have a relatively large age in the hotel industry, and the average value of their commitment and dedication to work engagement is low. The significant values of the three dimensions are all above 0.05 , indicating that there is no significant difference in the workforce input of hotel employees in the age group.

\section{Analysis of the Influence of Education on the Job Involvement of Hotel Staff}

In terms of the dynamism of work engagement, the employees with master's degree or above have the highest average value, and the employees with bachelor degree are the lowest; in terms of concentration, the employees with master's degree or above have the highest staff, and the employees with high school or below have the lowest degree of concentration; in terms of dedication, masters degree and The average of the above employees is the highest, and the number of employees with a bachelor degree is the lowest. Overall, employees with a master's degree or above have maintained a high level of professionalism in all aspects of their work commitment. The average value of employees with a bachelor degree in each dimension is low, which may be related to the characteristics of the hotel industry itself. Relatively low, undergraduate education is in a state of overachievement, which affects the employee's work engagement status. Observing the F value and significance of each variable, it was found that academic factors have a significant impact on the vitality dimension of hotel employees' work engagement.

\section{Analysis of the Influence of Departments on the Job Involvement of Hotel Staff}

In terms of the dynamism of work engagement, the average value of employees in the Ministry of Leisure and Recreation is the highest, and the average value of employees in the security department is the lowest. In terms of focus, the average value of the employees in the marketing department is the highest, and the average value in other departments is the lowest; in terms of dedication, the average value of the employees in the marketing department is the highest. The staff of the department is the lowest. Observing the $\mathrm{F}$ value and significance of each variable, it was found that the sectoral factors did not have a significant impact on the vitality, dedication, and focus of attention of hotel employees.

\section{E. Analysis of the Influence of Working Years on the Job Involvement of Hotel Staff}

In terms of the dynamism of work engagement, the average working life of employees is 3-5 years, and that of employees from 6 months to 1 year is the lowest. In terms of concentration, the average working life of employees is 1-3 years, and the employees are more than 5 years old. The average value is the lowest; in terms of dedication, the average value of employees is the highest in 1 to 3 years, and the average value of employees is the lowest in 5 years or more. Due to the labor-intensive and emotionally intensive nature of the hotel industry, employees who have worked for more than five years have had some job burnout, affecting their investment in work.

\section{F. Analysis of the Influence of the Position on the Job Involvement of Hotel Staff}

In terms of the dynamism of the job involvement, the average value of the middle managers is the highest, and the average value of the grassroots employees is the lowest. In terms of concentration, the average value of senior managers is the highest, and the average value of grassroots employees is the lowest; in terms of dedication, the average value of the middle managers is the highest, and grassroots employees the lowest mean value. Observing the $F$ value and significance of each variable, it was found that the position has a significant effect on the energy and dedication dimension of the hotel employee's job involvement, and has no significant influence on the focus dimension. After multiple comparisons by the LSD method, it was found that in the three dimensions of vitality, focus, and dedication of work engagement, both grass-roots employees and middlelevel managers had significant differences. The level of middle-level managers' work involvement was significantly higher than that of grass-roots employees; grass-roots managers and middle-level managers. Managers have significant differences in the dedication of their job involvements, and middle managers are more willing to contribute than grassroots managers.

\section{CONCLUSION}

As an important part of the service industry, the hotel industry has its own special characteristics, such as the simultaneous production and consumption, and the one-time service process. It has high requirements for employees' investment in the work process. The hotel is a comprehensive enterprise. The departments involved include the front-line reception departments for direct customer service such as catering, guest rooms, and front offices, as well as administrative security departments for finance, personnel, security, and engineering, and the quality of employees in different departments. The ability requirements are different. The article uses factor analysis to explore the three-dimensional structural model of hotel staff's job involvement, and analyzes the influence of individual characteristics of hotel staff on the job involvement from six aspects: gender, age, education, department, working years, and positions. The main conclusions are drawn as follows: 
There are no significant differences in gender, working years, and age characteristics among the three dimensions of hotel employee's work engagement, but there are significant differences in academic qualifications, departments, and positions. Employees with a bachelor degree in the work process are significantly less active than those with college or high school education or below. In terms of academic qualifications, the qualifications of hotel employees are generally low, but companies do not show high regard for highly educated personnel. Those with a bachelor's degree are graduating into hotel and corporate jobs. The content of the job is no worse than that of college or high school graduates. The company also has no explicit career planning for them, and most of their superiors (supervisors, department managers) are also college graduates or even graduates. This kind of psychological gap and loss will obviously affect the job involvement.

The career growth rate of the staff of the hotel marketing department is higher than that of other departments, and they also show a higher level of work commitment than other employees. The energy level of the marketing department staff is significantly higher than that of the staff of the security department and human resources department; the energy level of the staff of the finance department is also significantly higher than that of the security department; the degree of concentration of the staff of the food and beverage department is significantly lower than that of the staff of the marketing department and the finance department; marketing The employees' level of focus is significantly higher than that of the room, security, and finance departments; in the aspect of dedication, the marketing department has significant differences with the catering department, room department, front office department, security department, and other departments. The marketing department staff and these departments They are more willing to contribute than others; the dedication of the staff of the human resources department is significantly higher than that of the staff of the food and beverage department, the security department, and other departments.

The grassroots management of the hotel is still at the operation level of the hotel. Apart from the simple daily management work, it also needs to participate more in the hotel's front-line guest reception service; the middle management belongs to the management level of the hotel and considers the problem more. Overall, it is necessary to coordinate and coordinate the operations of the entire department. Compared with grass-roots managers, middlelevel managers are more willing to contribute and have higher levels of work commitment.

\section{REFERENCES}

[1] An Guangyi.A Review of Work Investment Research[J].Journal of Guangdong University of Technology(Social Sciences Edition),2010,10(3):30-33.

[2] Kahn.Psychological conditions of personal engagement and disengagement at work [J].Academy of Management Journal,1990,33(4):692-724.
[3] Schaufeli W B, Salanova M,Gonzalez-Roma,etal.The measurement of engagement and burnout:A confirmative analytic approach.Journal of Happiness Studies,2002,(3):71-92.

[4] Paully LM.,Alliger,GM.,\&Stone-Romero,E.F. Constiuct Validation of Two Instruments Designed to measure job Involvement and work centralty. Jounal of Applied Psychology.1994(79):224-228.

[5] Chen Weizheng, Li Jinping, Wu Jihong. Research on the influence of weaving climate on employee's work commitment and organizational commitment[J].Management Science.2006,19(6):18-23.

[6] Xu Yan. Research on the status quo of Chinese employees' work commitment [J]. Business Management. 2007, 1(491): 67-68.

[7] Liu Wenqing. Analysis of the Influencing Factors of Work Expenditure [J]. Market Modernization. 2007,(521): 313-314.

[8] Harter,J.K.,F.L.Schmidt and C.L.Keyes. Well-being in the workplace and its relationship to business outcomes: A review of the Gallup studies. In Flourishing: Positive psychology and the life well-lived. Washington, DC: AmericanPsychologicalAssociation,2003:205-224.

[9] Maslach,Leiter. The truth about burnout: How organization cause personal press what to do about it.San Francisco: Jossey Bass, 1997:321-325.

[10] Xu Yan. Questionnaire development and current status survey of employees' work input [D]. Lanzhou: Lanzhou University, 2005.

[11] Sheng Jiansen. Teachers' work input: structure and influencing factors [J]. Psychological Development and Education, 2006, (2): 108-112.

[12] May,D.R.,Gilson.R.L,Harter,L.M.The psychological conditions of meaningfulness safety and availability and the engagement of the human spirit at work. Journal of Occupational \& Organizational Psychology.2004,77(1):11-37.

[13] Zhang Shuwen, Gan Yiqun. Reliability and Validity Test of Workinput Scale (UWES)[J]. Chinese Journal of Clinical Psychology, 2005, 13(3):268-270 